\section{LAS RUINAS Y LAS SOMBRAS DE MANDERLEY}

\author{
María Donapetry \\ Universidad de Oxford
}

\begin{abstract}
The ruins and the shadows of Manderley explores possible reciprocal interpretative relations between Daphne du Maurier's novel Rebecca and Alfred Hitchcock's cinematic version. Some of the relevant aspects considered here are: the treatment of the Derridean "ruins of memory" within the novel and within Hitchcock himself, the differentiation and the confrontation of the protagonist as outsider vis á vis the world of Manderley's insiders, the iconic and symbolic values of the literary text and its filmic visualization, and the ethical positions implied by the choice or rejection of certain narrative devices in both works.
\end{abstract}

KEY WORDS: Adaptation; auteur; class; conscience; ethics; insider; memory; morals; outsider; ruins; shadows.

Ut pictura poiesis

(Como la pintura, asi es la poesía)

Horacio

En el manifesto crítico que Umberto Eco tituló Opera aperta en 1962, en el que analizó en detalle la diferencia entre una obra literaria y un producto consumible y repetible ad nauseam, se articula sin lugar a dudas que una obra literaria que se considere abierta no puede tener un sentido único y que su interpretación, por lo tanto, tampoco puede ser unívoca. Parto entonces de esta premisa (el texto literario es esencialmente abierto) para adentrarme en lo que hacen los cineastas que han basado sus películas en obras literarias.

Muchos críticos han sido los que han privilegiado el texto literario por encima de cualquier película que se haya hecho sobre éste simplemente porque la o las películas no reproducen el texto tal cual, como si este "tal cual" fuera algo tangible e inmutable, sobre todo en lo que respecta a la lectura del texto y a su interpretación. Desde el punto de vista del cine este acercamiento "reproductor" o "traductor" de un lenguaje (literario) a otro (fílmico) suele resultar estéril ya que la fidelidad que una película

\section{THE RUINS AND THE SHADOWS OF MANDERLEY}

RESUMEN: Las ruinas y las sombras de Manderley aborda posibles relaciones interpretativas reciprocas entre la novela de Daphne du Maurier Rebecca y la película homónima de Alfred Hitchcock. Algunos de los aspectos que se consideran relevantes en este estudio son: el tratamiento de las "ruinas de la memoria" derridianas dentro de la novela y del propio Hitchcock, la diferenciación y el enfrentamiento de la protagonista "externa" con el mundo de los "internos" de Manderley, los valores icónicos y simbólicos del texto literario y de la visualización fílmica, y las posiciones éticas que implican la elección o el rechazo de ciertos recursos narrativos en ambas obras.

PALABRAS CLAVE: Adaptación; auteur; clase; conciencia; externa; ética; interna; memoria; moral; ruinas; sombras.

pueda guardarle a un texto no garantiza nada de nada. El primer problema que plantea la idea de fidelidad al texto se podría articular en forma de pregunta: ¿a qué le puede ser fiel?; otro problema, e igualmente importante, es cómo puede serle fiel una película a un texto sin desvirtuarse completamente como película.

Es cierto, sin duda, que muchas películas intentan hacerse pasar por versiones visuales de un texto; y es igualmente cierto que estas películas suelen fracasar de manera estrepitosa simplemente porque no pueden, no saben o no quieren entender que la relación entre texto y película tiene mucho más que ver con conceptos, imágenes e interpretación que con palabras concretas o acciones concretas que se fijan en un texto y se intentan transferir a una película.

El signo verbal en sí tiene una iconicidad muy baja $y_{\text {, }} \sin$ embargo, tiene una función simbólica altísima, mientras que la imagen cinematográfica parte de una iconicidad obvia (es una imagen) y una función simbólica variable. Si quien hace una película sobre un texto no tiene en cuenta las muchas posibilidades simbólicas del texto, esto es: si cierra las posibilidades connotativas del texto, convertirá 

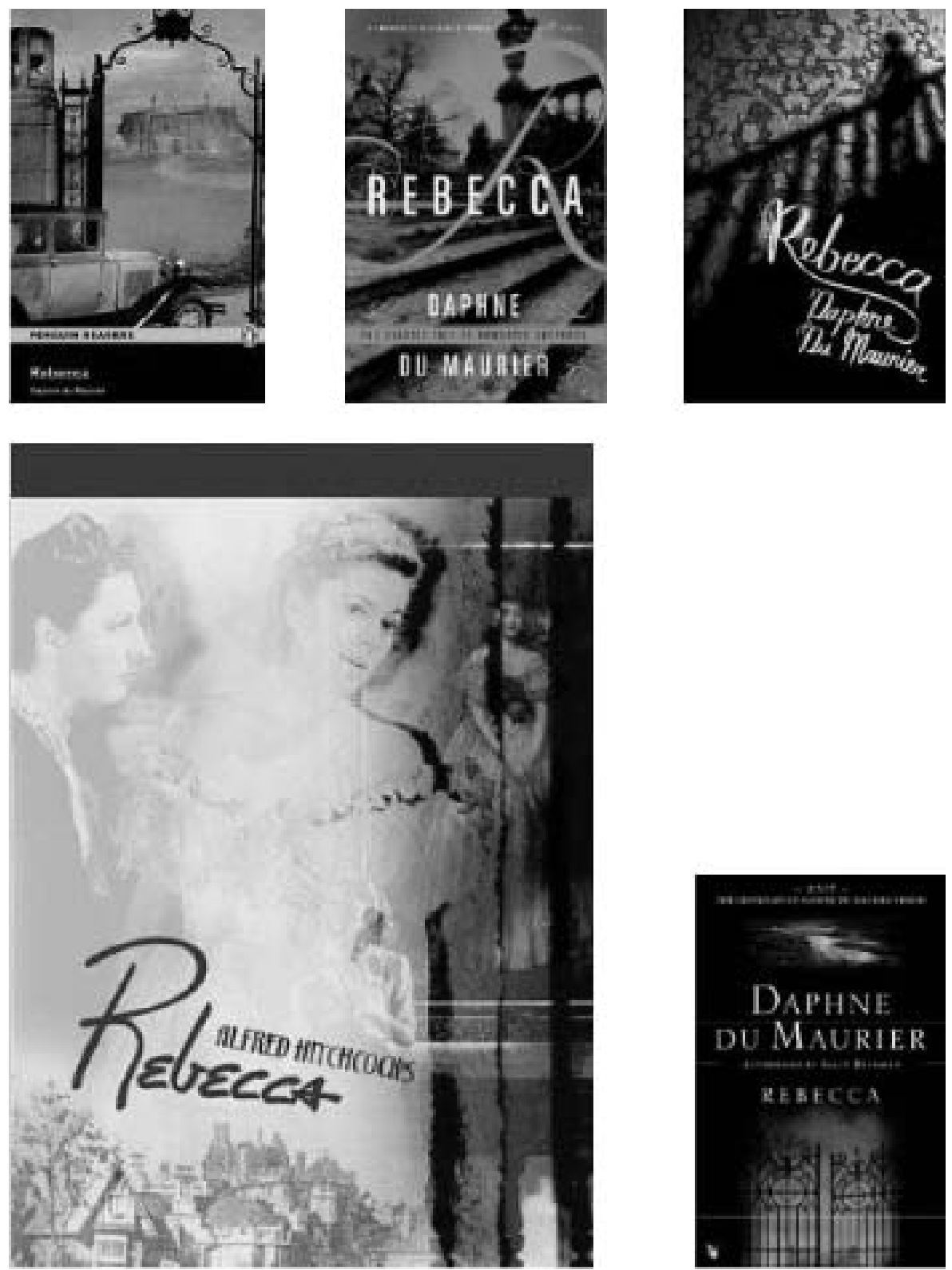

su película precisamente en la materialización visual de un mínimo común denominador. $\mathrm{Si}$, al contrario, parte y es consciente de la apertura del texto, la propia película podrá explorar varias, muchas o cualquiera de las posibilidades connotativas y aun sugerir otras que nos hagan volver al texto primigenio con nuevas miradas. Parafraseando a Christian Metz, el hecho de que toda producción esté condenada a ser connotativa es la clave de la dinámica de intercambio que existe entre dos obras. El texto original inicia un sistema diverso de actos de comunicación que pueden provocar una respuesta original en un miembro dado de su público. Así la selección de connotaciones del original junto al impacto emocional de éstas subyace a la nueva producción artística que, a su vez, traerá a colación nuevas connotaciones. Las novelas y las películas, al decir de Kaemilla Elliott (Elliott, 2003, 1), se relacionan como 
artes hermanas que comparten técnicas formales, públicos, valores, fuentes, arquetipos, estrategias narrativas y contextos. Lo que yo misma espero de un estudio de un texto literario y de una película basada en éste es una relación reciproca: que los significados se lean en ambas direcciones teniendo en cuenta precisamente lo que las dos artes comparten. Incluso cuando una película desfamiliariza el texto literario, o sea: cuando no reconocemos el texto literario a primera vista, el film lo resucita, lo revitaliza (si independientemente del texto es una buena película, por supuesto) porque nos fuerza a contemplar posibilidades interpretativas más allá de las que se encontrarían en una primera lectura del texto en lugar de procurarnos la comodidad de lo instantáneamente reconocible. Insisto en que la copia fiel de un texto, además de poco factible, suele venir causada por intereses económicos pero no estéticos ni éticos. Digamos que este proceder se aprovecha de la fama y el prestigio de una obra literaria para convertirla en un producto de consumo fácil, rápido y cómodo.

Mi tarea aquí no es la de estudiar simplemente la transformación de un texto verbal en "texto" fílmico", sino la de explorar algunas de las relaciones recíprocas de las que he hablado entre una obra y otra.

El cine de Hitchcock en general es lo menos parecido a lo que se llama cine literario. Sus películas funcionan como tales con total independencia de los textos en los que se puedan basar (y muchas de ellas están basadas en novelas) no sólo porque el propio Hitchcock se tome más o menos libertades a la hora de escoger o rechazar partes de un determinado texto, personajes o ambientes, sino también porque concibe su obra desde un principio como película y no como adaptación. Esto es: Hitchcock consigue que sus películas tengan sentido sin que haya que recurrir a un texto que las informe de alguna manera para hacerlas inteligibles. "En el principio fue el verbo" pasa a ser para Hitchcock "en el principio fue la imagen". El propio director británico insistía en declarar que él no leía novelas porque no le interesaban. Estas declaraciones, sin embargo, tienen que tomarse con ciertas dosis de escepticismo puesto que hay quien le describe como "devorador de libros". Hitchcock conocía personalmente a Daphne du Maurier, estaba al tanto de lo que escribía y, antes de ir a los Estados Unidos y empezar su carrera en Hollywood precisamente con Rebecca, ya había intentado comprar los derechos de la novela en Inglaterra. Creamos o no en lo ingenuo de sus declaraciones, lo que sí sabemos es que Hitchcock, como cualquier lector o espectador, interpretó selectivamente una historia y, a partir de las "ruinas de su memoria", rearticuló y produjo su propia historia.

El director francés François Truffaut desarrolló el concepto de "auteur" de cine y clasificó a Hitchcock precisamente como "auteur" por excelencia. Sus opiniones sobre el quehacer cinematográfico del director británico nos dan algunas claves de los intereses que hayan podido motivarle para hacer uso de varias novelas y cuentos cortos de Daphne du Maurier. Truffaut insiste en varios de sus textos sobre Hitchcock en que los factores comunes de sus películas son el temor, la subjetividad honesta, la intercambiabilidad de personajes, la identificación moral y a veces casi física entre dos seres humanos, los dilemas morales y, como apunta Bazin, el desequilibrio². Por su parte, la narrativa de Daphne du Maurier, particularmente la novela Rebecca, aunque la crítica se haya referido a ella constantemente como "neogótica", comparte con Hitchcock estos mismos factores. Dice Michel Serceau que "[e]। discurso hitchcokiano es siempre una búsqueda -decidida o impromptu- para resolver un enigma, llevada a cabo por un personaje cada vez más y más amenazado por su propia obstinación" (Serceau, 1989, 139) ${ }^{3}$. Hitchcock sin duda crea situaciones de suspense en las que las tensiones de los personajes se transfieren al público, pero lo que nos interesa es que estas tensiones, además de que puedan producir un placer un tanto masoquista y ansioso en el público, activan los sentimientos de ese público yendo más allá del mero interés por saber qué va a pasar a continuación. Dicho de otra manera: hace que quien ve la película se implique en los dilemas morales de los personajes, además de interesarse en las resoluciones de los dramas. Daphne du Maurier, es cierto, utiliza elementos reconocibles de la novela "gótica" tales como la mansión aislada, tormentas y calores, incendios destructores, una "loca" del ático, personajes misteriosos y oscuros y personajes femeninos a veces desvalidos y claramente victimizables, a veces dominantes e inescrutables. Pero me temo que tener en cuenta estos elementos exclusivamente sería quedarse con los aspectos formales de su novela sin entrar en cómo se implica el lector en la historia y con los personajes. Como en el caso de Hitchcock, Du Maurier sitúa a su personaje principal en una búsqueda que la sumerge cada vez más en oscuridades de su propia creación, en historias que ella misma crea, que la condicionan física y psicológicamente y de las que la persona que lee tiene que participar por necesidad.

ARBOR CLXXXVI 741 enero-febrero [2010] 43-52 ISSN: 0210-1963

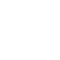


Hitchcock siempre se refirió a Rebecca aseverando que no era una película "Hitchcock". Existen multitud de detalles periféricos a la película que pueden dar cuenta de tan extraordinaria declaración: David O'Selznick, el productor, impuso su visión de la "adaptación" de la novela y rechazó varias veces los cambios que Hitchcock propuso, el propio Hitchcock se sometió a esta dictadura porque era su primera película en Hollywood, etc. Lo que O'Selznick quería a toda costa era "fidelidad" al texto con algún cambio "menor" que convirtiera la película en una historia edificante para el gran público acostumbrado a Hollywood y a su código moral. Uno de estos cambios fue que Maxim, en vez de matar a Rebecca como ocurre en la novela, es mero testigo del golpe mortal que la propia Rebecca se da accidentalmente. Hitchcock también tuvo que someterse a los mandatos de los estudios en cuanto a selección de actores/estrellas de la pantalla. Sin embargo, creo que Rebecca es sin duda una película "Hitchcock" a pesar de las interferencias orientadas hacia la comodificación endémica de O'Selznick y de los estudios de Hollywood. Obviamente estos elementos estaban totalmente fuera del control de Hitchcock pero también hay otros elementos "periféricos" a la película, pero no al propio Hitchcock, que le añaden una cualidad personal hitchcokiana a Rebecca: su jesuitica búsqueda de orden, la necesidad de enfrentarse al miedo que cualquier británico del momento habia sentido durante la guerra y su conciencia de que la "alta" sociedad inglesa agonizaba y que ello significaba un paso adelante. Por otra parte, la propia Du Maurier lleva a su texto o evoca en su novela algunos de sus propios elementos periféricos (no podría ser de otra manera): un padre 0 figura masculina imponente y dominante al que hay que aplacar, lo que queda de Jane Eyre en las propias ruinas de su memoria o la afición a las mansiones señoriales de su Cornualles natal. Lo importante es que estos elementos periféricos -las opiniones de O'Selznick, las decisiones de los estudios, las ideas y vivencias personales de Hitchcock y las de Du Maurier-, añaden posibilidades interpretativas a la película, al texto y a las relaciones entre ambas sin que una elección interpretativa vaya en detrimento de muchas otras.

Para organizar de alguna manera mi acercamiento a la película de Hitchcock destacaré algunas diferencias argumentales que mantiene con la novela homónima. Podrian apuntarse muchas más; algunas relacionadas con lugares donde ocurre la acción, otras con la participación de cier- tos personajes, aun otras con la eliminación de personajes que, por lo que quiera que fuera, Hitchcock consideró irrelevantes 0 innecesarios para la trama de su película. Las diferencias a las que me referiré creo que son particularmente indicativas de lo que Hitchcock quiere contarnos a partir de la novela de Du Maurier y dan cabida a una posible lectura precisamente de la Rebecca literaria. Nos interesamos, pues, en estas diferencias en particular y en su puesta en escena, en la visualización fílmica que convierte el relato "a ciegas" de la ${ }^{4}$ narradora en la novela en un drama entre "internos" y "externa" que se resuelve en último término con la destrucción total de Manderley -el límite divisor entre ella y los otros personajes ${ }^{5}$.

\section{VOZ EN OFF, NARRACIÓN ONÍRICA Y LAS RUINAS DE MANDERLEY}

Tanto la novela Rebecca de Du Maurier como la película homónima de Hitchcock empiezan con la voz de la anónima protagonista recordando su vuelta onírica a Manderley como introducción a una narración retrospectiva que constituirá la historia que se nos va a relatar: "Last night I dreamt I went to Manderley again. It seemed to me I stood by the irongate leading to the drive, and for a while I could not enter for the way was barred to me". Hitchcock utiliza la voz en off y visualiza el relato onírico de este Yo haciendo que la cámara y la voz se identifiquen y produzcan así un alineamiento entre el espectador y Yo. Esta escena no tiene sutura ${ }^{6}$ en su sentido más clásico (no vemos a Yo soñando o presente en su sueño) $y$, por lo tanto, nos sumerge de lleno en la subjetividad de la voz incorpórea sin tener pistas ni de tiempo ni de lugar. "Anoche" no puede significar nada si no sabemos desde qué "hoy" o "ahora" se nos habla. Este presente relativo no va a aparecer nunca en la película, con lo cual el público y la voz parecen estar en el mismo presente desde el que Yo habla. El resto de la historia, contada retrospectivamente, lo constituye en el libro el testimonio de Yo sobre sus experiencias y relación con Manderley y sus habitantes. El testimonio natural narrativo de la novela, como observa Derrida refiriéndose a los testimonios en general, "sustituye la percepción con la narración. No puede ver, mostrar y hablar a la vez..." (Derrida, 1990, 106) ${ }^{7}$, mientras que Hitchcock, a partir de la primera identificación de la cámara con la voz, nos implica emotivamente en la historia y nos convierte en testigos 
oculares de su desarrollo con Yo misma como personaje observable. Participamos así de las tensiones psicológicas de Yo no sólo porque nos hayamos alineado con ella, como ocurre en la novela, sino porque Hitchcock nos convierte en testigos directos de esas tensiones. Yo nos ofrece una visión parcial de las ruinas de su memoria. El sueño de Yo presupone los ojos cerrados, una ceguera "visionaria" temporal que nos intenta explicar algo fuera del control consciente del sujeto. La secuencia del sueño para nosotros enfatiza precisamente esa falta de significado claro y provoca un deseo de saber, de desentrañar un misterio. Para la protagonista el sueño le sirve de meditación sobre el pasado, sobre las ruinas de Manderley y de su vida hasta el momento de contárnosla. En la novela Yo habla desde un presente feliz y equilibrado que se ha conseguido con gran esfuerzo y dolor. Hitchcock, como ya he mencionado, no nos proporciona esa satisfacción a priori. No lo hace, creo yo, porque su foco de atención está permanentemente ligado a las tensiones dramáticas y a una adquisición de conciencia y de equilibrio que va paralela a la de los personajes de la historia que la película nos cuenta.

Volviendo a la voz en off, el efecto que produce en el público es el de ver lo que Yo no ve con sus sentidos sino con sus recuerdos emotivos. Lo que vemos son sombras tenebrosas y amenazadoras que permanecerán en nuestra memoria emotiva y visual. Manderley, pues, aparece desde el principio como un fantasma del pasado al que, por lo menos la protagonista, no desea volver $y$, sin embargo, sabemos que tenemos que volver con ella si queremos saber la historia. Este juego narrativo intensamente subjetivo implica a quien lee y a quien mira respectivamente en la historia personal de la protagonista. Es más, nos advierte que lo que vayamos a aprender está fuertemente sujeto a un punto de vista único: el de ese "Yo" con voz pero sin cuerpo que nos oriente. También este principio nos da varias claves sobre las cuestiones que van a servirles tanto a Du Maurier como a Hitchcock para llevar adelante sus respectivas narraciones: los deseos y temores de la anónima protagonista. Algunas de las claves interpretativas son de tiempo y de lugar. "Yo" ha sido una persona ajena a un mundo, el mundo de Manderley, que la ha atraído pero que la mantiene fuera de manera evidente. Esas rejas le permiten ver pero le recuerdan constantemente que está fuera y que su entrada será como poco trabajosa. Sigue contándonos que cuando, en su sueño, logra entrar a la propiedad, la naturaleza ha convertido el camino y los jardines en algo selvático y amenazador, y lo que queda de la mansión recuerda al grandioso Manderley, ejemplo del zénit de la civilización y la belleza ${ }^{8}$, pero reducido a ruinas iluminadas fantasmagóricamente por la luz de la luna. Irónicamente, a lo largo de la novela y de la película aprenderemos que, para el personaje central de Manderley, para Maxim -el "interno" por antonomasia- Manderley ya está contaminado, ya ha perdido su atractivo porque, en definitiva, es la sociedad real de dentro de Manderley la que se ha valido de su superficie brillante para esconder todo tipo de suciedad y decadencia moral. Él es, sin duda, un "interno" pero un "interno" que desea profundamente salir, aunque no lo averigüemos hasta bien mediada la historia. Durante el resto de la película, y prácticamente hasta la confesión de Maxim, las sombras y las ruinas de Manderley se visualizan en cada escena como ecos del principio onírico y anuncios premonitorios del final.

Desde que Yo aparece en Monte Carlo con la odiosa Sra. Van Hopper y ya ha conocido a Maxim, las menciones de Manderley y, en especial, de Rebecca provocan oscurecimientos y estremecimientos en la protagonista que se visualizan con sombras que la envuelven intermitentemente. Quizás una de las secuencias más fáciles de recordar es cuando, ya casada con Maxim, entra en el despacho de Rebecca, "the morning room" en Manderley, se sienta al escritorio, observa lo que hay encima, se fija en la agenda de Rebecca repleta de títulos nobiliarios, se siente totalmente fuera de lugar social, psíquica y físicamente y de manera descuidada tropieza con una figurita de porcelana y la tira al suelo. La figurita es un valioso cupido que, una vez hecho pedazos, Yo se apresura a esconder en uno de los cajones del escritorio. La cámara nos ofrece primeros planos de la cara de Yo cuando se le cae el cupido y de sus manos juntando los trozos de porcelana y tapándolos apresuradamente con papeles. En esta escena Hitchcock no deja apenas espacio entre la cara y las manos de Yo y nosotros de modo que nos sintamos cómplices de la torpeza y de la alienación de Yo. Más adelante, cuanto más se habla del cupido, de su belleza y de su valor, peor se siente Yo y nosotros; primero porque pronto se sabrá que ha sido Yo quien lo ha roto; y segundo, porque no es casualidad que sea un cupido y que haya pertenecido a Rebecca. Siempre que se menciona a Rebecca y su relación con Maxim se las califica invariablemente de preciosas, como todo lo que pertenece a Manderley. Yo ha roto el cupido sin intención; o, quizás, y totalmente inconscientemente, eso es lo que

ARBOR CLXXXVI 741 enero-febrero [2010] 43-52 ISSN: 0210-1963

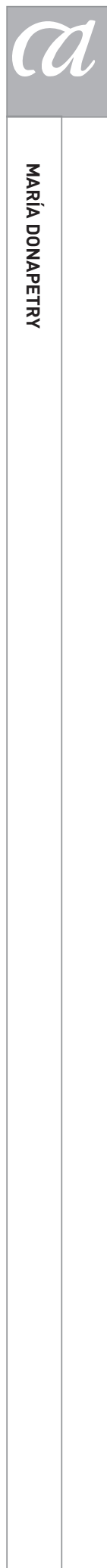


ha querido hacer. Aunque ni Yo ni nosotros lo sepamos en ese momento, su comportamiento típico de "externa" es lo que en definitiva va a liberar a Maxim de sus demonios. El cupido, como el amor de Rebecca, está hueco y se destroza con un inocente movimiento. Estas pequeñas "ruinas" del cupido, tan especialmente enfatizadas por Hitchcock, resultan ser un eco de las que ya viéramos en el sueño que abre la película.

Otro de los momentos absolutamente "Hitchcock" de la película es cuando Maxim y Yo están viendo la película de su viaje de bodas y el mayordomo interrumpe la sesión para anunciar que otro criado ha sufrido las iras de la Sra. Danvers acusándole precisamente de haber robado el cupido. Esta escena está dominada por lo estrictamente fílmico. No sólo están viendo una película (reproduciendo nuestra situación de espectadores) sino que el montaje de escenas cortadas de la película del viaje de bodas y las secuencias de Maxim y Yo en Manderley mirando, discutiendo sobre su "felicidad", resolviendo el problema del cupido y volviendo a mirar la película, nos sumergen en tensiones de naturaleza similar a las de los personajes. La película que Maxim y Yo ven nos presenta a una pareja enamorada y feliz muy distinta a la pareja que vemos discutiendo y tratando de disimular su distanciamiento en Manderley. No hay un puente visual o emotivo que nos ayude a poner de acuerdo lo filmado por ellos con su entorno presente. Lo que la película de Hitchcock logra es hacernos participar del desconocimiento, el temor y la desesperación de Yo. A este montaje y "contenido" argumental se le añade el juego de luces y sombras de la escena. El hecho de que la iluminación de los personajes (Maxim y viendo la película) venga de la película que están viendo y se interrumpa con un drama doméstico (que resulta mucho más significativo para Yo, como hemos visto) y la vuelta a ver al Maxim del viaje de bodas filmado sonriente, haciendo muecas y abrazado a Yo mientras el Maxim en Manderley y Yo están sumidos en una oscuridad física y emotiva, nos remite otra vez a la incertidumbre ominosa del principio. De nuevo Manderley proyecta sus sombras sobre los personajes.

\section{LA CONFESIÓN}

La confesión de Maxim es el momento crucial de la historia. Hasta ahí, la "externa" ha tratado por todos los medios de adaptarse y ajustarse a Manderley y a lo que cree que representa para Maxim. Yo ha tratado de comportarse como una "interna" sin ser consciente (o no parecer consciente) de que su valor y su atractivo para Maxim reside precisamente en su no ser una "interna". Si Maxim se ha enamorado de ella, es porque Yo es o parece ser el polo opuesto a Rebecca. Cuando Yo se disfraza, siguiendo el consejo de la Sra. Danvers, de Lady Caroline de Winter (como ya había hecho Rebecca en otra ocasión) admiramos inocentemente su triunfal bajada por las escaleras hasta que Maxim y su hermana la miran horrorizados. Ni Yo ni nosotros sabemos el porqué del rechazo pero más adelante averiguaremos que, por lo menos para Maxim, la reacción no surge del dolor de haber perdido a Rebecca sino de que $Y_{0}$ intente parecerse en lo más mínimo a su primera mujer, que intente ocupar la ausencia de Rebecca. Yo, por su parte, ha intentado presentarle batalla al fantasma, al recuerdo de Rebecca, inútilmente. No sólo se enfrenta a un boicoteo constante por parte de la Sra. Danvers, sino que ella misma invoca al fantasma de Rebecca creando y recreando una historia de amor entre Rebecca y Maxim que nunca existió. El símbolo que evoca la sombra de Rebecca es la inicial bordada o impresa por todas partes en lo que fueron los dominios de Rebecca. En la novela es el recuerdo de una $R$ que Yo observa en un libro de poemas que algún día Rebecca le regaló a Maxim y que Maxim, a su vez, le presta a Yo en Monte Carlo. Cuando Maxim ya le ha propuesto matrimonio, Yo corta la página donde aparece la $R$ de Rebecca y quema los trozos de papel con la tinta $y_{\text {, }}$ justo después de decirle a la Sra. Van Hopper que se van a casar y después de los atroces comentarios de ésta hacia Yo, ella se consuela pensando: "A new confidence had been born in me when I burnt that page and scattered the fragments. The past would not exist for either of us, we were starting afresh, he and I. The past had blown away like the ashes in the waste paper basket. I was going to be Mrs. de Winter. I was going to live in Manderley". En la película, la $R$ es ubicua en Manderley y sólo su desaparición total le dará paz a Yo. Pero no es sólo esta $\mathrm{R}$ la que le recuerda a Yo su calidad de intrusa; las imponentes dimensiones de la habitación de Rebecca, la vida que la Sra. Danvers le da a cada objeto que ha pertenecido a Rebecca e incluso la pasión desmesurada que el ama de llaves aún siente por su señora convierten la ausencia de Rebecca en algo casi tangible y aparentemente superior a sus fuerzas. El caso es que la noche de la confesión de Maxim, cuando se han descubierto el barco y el cadáver de Rebecca (ya no sólo 
la letra inicial de un nombre sino un cuerpo), se convierte en una revelación narrativa y psicológica tanto para Yo como para nosotros (siempre fielmente alineados con ella, por supuesto). Hasta ese momento Maxim no ha hecho grandes esfuerzos por disipar y ahuyentar los fantasmas que ensombrecen la vida de Yo en Manderley simplemente porque no es consciente de sus esfuerzos y porque sus demonios -Rebecca- no son proyecciones de una mente imaginativa sino recuerdos de algo vivido. A diferencia de la novela, el lugar de la confesión que Hitchcock escoge forma parte de Manderley pero carece del glamour y la grandiosidad de la biblioteca de la mansión. La casita de la playa ha sido la "cueva de la bruja", el lugar de pecado donde Rebecca solía llevar a su o a sus amantes, así que tiene sentido que también sea el lugar de confesión del pecado de Maxim. Aunque en la película Maxim relata la muerte de Rebecca como resultado de un accidente, su confesión es de la intención que tenía de matarla a ella sola o a ella y a Favell, el amante de turno de Rebecca. La explicación de cómo se desarrollaron las circunstancias del "accidente" y nuestro entendimiento de las mismas depende, naturalmente, de la confesión verbal de Maxim, pero de igual peso es el movimiento de la cámara y lo que nos muestra. Rebecca ya ha muerto y su cadáver está en el barco hundido cerca de la playa, pero la cámara enfoca cada lugar de cada movimiento de Rebecca y de cada objeto que estaba presente durante el enfrentamiento final entre Rebecca y Maxim. Las "ruinas de la memoria" de Maxim, su testimonio, se ven reforzadas por el objetivo de la cámara: Maxim reproduce el diálogo final entre Rebecca y él mientras la cámara se posiciona como testigo ocular que no se corresponde necesariamente a la mirada de Yo pero sí a la nuestra. El resultado es que el relato de Maxim se oye como voz en off que envuelve la ausencia/ presencia de Rebecca.

Esta secuencia no deja de recordarnos a la del principio de la película. Los destacados claro-oscuros que envuelven la desesperación de Maxim, que no su arrepentimiento, se disuelven momentáneamente toda vez que Yo internaliza la frase que la libera: Maxim no amaba a Rebecca. Al aprender que Maxim la ama a ella y no a Rebecca, Yo adquiere conciencia e iniciativa en lo que hace. Hasta esa confesión, los actos de Yo no tienen dirección concreta porque desconoce el territorio en casi todos los sentidos. Yo asume el papel de confesor y "absuelve" a Maxim porque sabe que está en posición de hacerlo: entiende que
Maxim ya ha sufrido su penitencia. Manderley ya no es el epítome de la sofisticación inalcanzable para Yo sino el lugar y hasta cierto punto la causa del sufrimiento para los dos. En su confesión Maxim abjura de los valores por los que se regía en su juventud y mientras estuvo casado con Rebecca. Esta retractación sui generis le convierte en un hombre normal y corriente, vulnerable, un hombre al que Yo puede comprender y no simplemente admirar desde lejos. Según Tania Modleski, "the heroine, actively desiring the process by which all of Rebecca's apparently positive attributes are proved to be worthless, can offer the male nothing more than a vacuous self. In the film's fantasy, a woman's fantasy par excellence, the hero highly prizes the woman's insignificance" (Modleski, 1989, 50). Mi interpretación no podría estar más lejos: lo que Maxim valora no es la insignificancia de Yo sino la integridad moral que ella tiene y que él había perdido con Rebecca, su capacidad de amar y su capacidad y voluntad de perdonarle. A pesar de este descubrimiento "iluminador", el juego de sombras que Hitchcock materializa en la escena fuerza al público a tener que interpretar las luces, los claros morales y narrativos por sí mismo.

\section{EL INCENDIO Y LA INMOLACIÓN/SUICIDIO de la Sra. Danvers}

Manderley acaba en llamas tanto en la novela como en la película, pero no ocurre exactamente de la misma manera. Yo ha absuelto a Maxim pero la Sra. Danvers no. Mientras Yo espera pacientemente a que Maxim y Frank vuelvan de su visita al médico de Rebecca en Londres, Favell Ilama a la Sra. Danvers y le comunica que Rebecca se suicidó porque tenía cáncer. Mientras la señora Danvers pudiera creer que había un culpable por la muerte de Rebecca y que sería juzgado por un tribunal, podía disfrutar de una venganza "legítima". Si los representantes de la ley aceptan que la causa de la muerte de Rebecca se debe a circunstancias totalmente fuera del control de Maxim, nadie pagará las culpas y ella tendrá que hacer justicia. Podríamos pensar que la venganza perfecta de la señora Danvers sería matar a Yo, además de incendiar Manderley, y quitarle todo a Maxim como castigo. Pero la señora Danvers es definitivamente una "interna" en Manderley y actúa como tal. Destruye lo que cree que reúne y ejemplifica valores absolutos y eternos para Maxim y no considera que la existencia 
fuera de Manderley pueda significar nada especial para él. A diferencia de nosotros, ella no sabe que Maxim se ha retractado de sus antiguas creencias, que Manderley y todo lo que representaba se habian convertido en su cárcel del alma. Si seguimos algunas de las pistas que Hitchcock nos ha proporcionado a lo largo de la película, el hecho de que decida prenderle fuego a Manderley y perecer en él resulta en la liberación última para Yo y para Maxim. En la novela Maxim y Yo son quienes descubren el incendio de Manderley mientras vuelven conduciendo desde Londres. En la película, Maxim vuelve de Londres con su fiel secretario mientras Yo se queda esperando en Manderley. Este cambio de situación de personajes, sin duda, crea una tensión especial en la película porque el público no sabe durante algunos momentos dónde está Yo: si está atrapada en el incendio o no. Pero, más allá de ese momentáneo suspense, la atención se concentra en la auto-inmolación de la señora Danvers y en el inevitable asombro que provoca en el público. Cuando Maxim llega por fin a Manderley y se encuentra con Yo, se abrazan. Yo le indica a Maxim que mire hacia la ventana de la habitación de Rebecca y ya no volvemos a verlos. Miramos y vemos lo que se supone que están viendo; pero viajamos con la cámara (como Yo hace en su visión onírica de Manderley al principio) hacia el fuego y hacia la muerte de la señora Danvers, y nos acercamos al final absoluto: un primer plano de la $R$ envuelta en Ilamas. La expresión última en la cara de la señora Danvers se puede interpretar como de total éxtasis y gozo, como la de una mártir que ve llegar su hora eterna. También puede ser la expresión de su "locura de amor", de ver por fin satisfecho su deseo de unirse a Rebecca para siempre; o la expresión de su triunfo vengador. La toma final, como ya he apuntado, es de las Ilamas alcanzando la cama de Rebecca y la $\mathrm{R}$ bordada precisamente por la señora Danvers en la funda de su camisón. La última $R$, metonimia visual por excelencia del fantasma del mal, desaparece por fin y se convierte en cenizas. Si consideramos que la $\mathrm{R}$ de Rebecca también estaba grabada a fuego en el espíritu de Maxim, el incendio supone un exorcismo de esa prisión del alma en la que Maxim se vio atrapado desde la confesión de Rebecca sobre sus planes para su matrimonio con él hasta la propia confesión que éste le hace a Yo. El momento en el que Yo quema la $R$ en la novela es un vano intento de deshacerse de su miedo y sus celos de Rebecca mucho antes de saber algo más de la propia Rebecca que los comentarios siempre elogiosos de la señora Van Hopper. En la película la $\mathrm{R}$ ardiente nos deja con una victoria moral tanto para Maxim como para Yo misma. La ley de "Ios internos" se acaba definitivamente con el incendio de Manderley y con la inmolación de la señora Danvers.

Entre los recuerdos de Yo del principio de la novela se encuentran frases que rezuman nostalgia por la vida que habria podido tener en Manderley: "The house was a sepulcher, our fear and suffering lay buried in the ruins. There would be no resurrection. When I thought of Manderley in my waking hours I would not be bitter. I should think of it as it might have been, could I have lived there without fear". La satisfacción que Hitchcock nos proporciona con su final dantesco es el de intuir que los protagonistas pueden empezar de nuevo fuera de Manderley, sin nostalgia. Para llegar a ese punto tanto Maxim como Yo y, en último término, el público han tenido que sufrir, que pasar por su prueba de fuego.

Sin duda, la posición ética de Hitchcock difiere de la de Daphne du Maurier; y no podría ser de otra manera porque Hitchcock, y la intervención de todos los factores periféricos de los que hablé anteriormente, abren la novela de Du Maurier a otras posibilidades interpretativas. Hitchcock le es "fiel" a la novela en toda una serie de detalles, personajes, partes de la historia, etc., pero subordina el texto a una visión profundamente sesgada por valores morales y fílmicos concretos. La redención no les llega a los personajes tanto a través del amor de los protagonistas como de la inocencia, el desconocimiento y la enajenación de Yo. Naturalmente, Yo tiene que llegar a saber y continuar siéndole fiel a Maxim pero sin convertirse en parte integrante del mundo de Manderley. Según Charles Taylor, "To know who $u$ are is to be oriented in moral space, a space in which questions arise about what is good or bad, what is worth doing and what not, what has meaning and importance for $u$ and what is trivial and secondary" (Taylor, 1989, 94). Este principio de auto-conocimiento es el que prevalece en la película de Hitchcock con respecto a sus protagonistas. Creo que Hitchcock definitivamente considera Manderley en su contexto social como uno de los síntomas obvios de lo insidiosamente banal (como la figurita del cupido) y su película intenta decir algo diferente, construir un significado con valores y esperanzas distintas a las de Du Maurier en cuanto a lo que merece la pena para el ser humano. Las tensiones a las que nos ha sometido no sólo satisfacen las ansias más o menos masoquistas del espectador de películas de suspense, sino que provocan (o pueden provocar) 
cuestiones que sólo el espectador puede responder en su fuero interno. No deja de sorprender que sea la película de Hitchcock mismo con sus "desviaciones" del texto de Du Maurier la que pone el peso de un cambio profundo en la estructura social y eminentemente patriarcal en los hombros de Yo, la externa. El mundo de Maxim se vio sacudido por una mujer, Rebecca, y su salida a una vida mejor se la proporciona otra mujer. Como observa Modleski $(1989,3)$, las mujeres del cine de Hitchcock se resisten constantemente a la asimilación patriarcal.

En cuanto a los valores fílmicos, Hitchcock crea un lenguaje visual en el que las sombras adquieren el mismo protagonismo que los personajes. Esta profusión de sombras, junto a los muy escogidos primeros planos y tomas no "suturadas", forman parte de su manera personal de darle profundidad visual e ideológica a Rebecca como drama de suspense. A pesar de sus protestas en sentido contrario, Hitchcock crea una obra de arte propia, una película "Hitchcock", en el sentido de que su Rebecca es el producto deliberado de su mente y de su habilidad como director de cine. Su película está muy lejos de repetir lo que Daphne du Maurier escribió porque intenta, y logra ampliamente, ir más allá de lo superficial. Es tarea de quien ve la película y de quien lee la novela hacer lo mismo.

\section{NOTAS}

1 Se sale de mi tema abundar en la discusión sobre la comparación entre el lenguaje cinematográfico y el lenguaje literario. Son muchos los aspectos que comparten la narrativa literaria y la fílmica, de ahí que merezca la pena este tipo de estudio; $\sin$ embargo, es preciso ser consciente de que son lenguajes de naturalezas bien distintas.

2 François Truffaut en The Films in my Life recoge toda una serie de reseñas sobre películas de los directores que considera "auteurs". Por supesto, dedica unas cuantas páginas a varias películas de Hitchcock y cita también la opinión de André Bazin sobre la calidad del suspense de su obra (80). Otra de las obras importantes de Truffaut sobre Hitchcock es Hitchcock en la que reúne una serie de entrevistas con el propio Hitchcock $y_{1}$ naturalmente, aporta sus propias opiniones.

3 "Le récit hitchcokien est toujours une enquête-décidée ou improptue-pour résourdre une énigme, menée par un personage de plus en plus menacé par sa obstination même".
4 Dado que la protagonista y narradora no tiene nombre propio, usaré Yo para referirme a ella como personaje.

5 Uso aquí "interno" y "externa" como traducciones útiles de las palabras en inglés "insider" y "outsider".

6 Sobre el término "sutura" en el cine véase, entre otros, Jean-Pierre Oudart, "Cinema and Suture" en The Sypmtom y Susan Hayward (2000, 378-385).

7 "substitue le récit à la perception. II ne peut voir, montrer et parler en même temps..." Traducción mía.

8 El nombre de Manderley recuerda fonéticamente a la ciudad Mandalay en Burma. Se escribe Rebecca en 1938 y Burma, administrada como parte de la India hasta 1937, es una de las colonias más preciadas del Imperio Británico hasta que en 1942 la ocupan los japoneses.

\section{BIBLIOGRAFÍA}

Derrida, Jacques (1990): Mémoiresd'aveugle. L'autoportrait et autres ruines, Editions de la Réunion des musées nationaux, 106.
Aceptado: 3 de abril de 2009 
Du Maurier, Daphne (1977): Rebecca, Book Club Associates.

Eagleton, Terry (1996): The Illusions of Postmodernism, Blackwell.

Elliott, Kaemilla (2003): Rethinking The Novel/Film Debate, Berkeley, University of Cambridge Press.

Hayward, Susan (2000): Cinema Studies. The Key Concepts, London and New York, Routledge: 378-385.

Metz, Christian (1973): Lenguaje y cine, Barcelona, Planeta.
Modleski, Tania (1989): The Women Who Knew Too Much. Hitchcock and Feminist Theory, London, Routledge.

Oudart, Jean Pierre: "Cinema and Suture", en The Symptom, online journal for Lacan.com http://www.lacan. com/symptom8-articles/oudart8. htlm

Serceau, Michel (1989): "Alfred Hitchcock: l'image à la rencontre", CinémAction, No 53, $120 \mathrm{~F}$ 4e trimestre-octobre, 139.
Taylor, Charles (1989): Sources of the Self, Cambridge, Cambridge University Press.

Truffaut, François (1984): Hitchcock, New York, Simon \& Schuster.

- $\quad$ (1994): The Films in my Life, New York, De Cappo Press.

\section{FILMOGRAFÍA}

Rebecca (Dir. Alfred Hitchcock, 1940). 